197 DYNAMIC HIP SCREW SURGERY UNDER PERIPHERAL NERVE BLOCKADE ONLY

D Bendel*, C Broe, A Pal, T Edwards, T Packer, B Bellew. St Mary's Hospital, Imperial College Healthcare NHS Trust, London, UK

10.1136/rapm-2021-ESRA.197

Background and Aims We present the management of an elderly ASA 4 female with a left-sided fractured neck of femur. Comorbidities included stable angina, asthma and COPD. Acutely, a superimposed chest infection precipitated respiratory distress and hypoxaemia. Clopidogrel, stopped the day before, precluded neuraxial anaesthesia. The patient's Surgical Outcome Risk Tool score for mortality within 30 days was $15 \%$. Following multi-disciplinary input, a decision to operate under regional anaesthesia was made.

Methods The femoral, obturator, lateral cutaneous femoral nerve and sciatic nerves were successfully blocked, and a dynamic hip screw was inserted with minimal risk to the patient. The patient followed an uncomplicated intraoperative course.

Results Post-operatively, the patient remained comfortable. Following a period of transnasal humidified rapid-insufflation ventilatory exchange in recovery and intensive care review, the patient was transferred to the ward under the joint care of the orthogeriatricians and orthopaedics. She remained comfortable on oral analgesics on review the following day.

Conclusions This case demonstrates that NOF surgery can be done under peripheral nerve blockade only. It is apparent to us that there may be several subsets of high risk patients in whom this strategy is preferable to central neuraxial blockade or general anaesthesia, and we expect this to become increasingly common in the future.

\section{FASCIAL PLANE BLOCKS IN TOTAL ABDOMINAL HYSTERECTOMY: A SYSTEMATIC REVIEW AND NETWORK META-ANALYSIS}

${ }^{1} \mathrm{G}-\mathrm{H}$ Bai*${ }^{*},{ }^{1} \mathrm{M}-\mathrm{C}$ Tsai, ${ }^{2} \mathrm{~T}-\mathrm{Y}$ Hung, ${ }^{3} \mathrm{~W}-\mathrm{H}$ Hou. ${ }^{1}$ School of Medicine, College of Medicine, Taipei Medical University, Taipei City, Taiwan, Province of China; ${ }^{2}$ Department of Anesthesiology, Taipei Mackay Memorial Hospital, Taipei City, Taiwan, Province of China; ${ }^{3}$ Department of Physical Medicine and Rehabilitation, Center of Evidence-based Medicine, Taipei Medical University Hospital, Taipei City, Taiwan, Province of China

\subsection{6/rapm-2021-ESRA. 198}

Background and Aims Fascial plane blocks can provide effective analgesia for abdominal surgeries. However, different randomized controlled trials (RCTs) showed controversial results in total abdominal hysterectomy and there were limited data directly comparing the techniques. We conducted a network meta-analysis of RCTs to investigate the effectiveness of transversus abdominis plane (TAP) block, quadratus lumborum (QL) block and erector spine plane (ESP) block in patients with total abdominal hysterectomy.

Methods We searched PubMed, Embase, Cochrane Library, and CINAHL from inception to June 2021. Random-effects network meta-analyses were performed for comparing the fascial plane blocks. The primary outcome was 24 hours morphine equivalent consumption and the secondary outcome included time to first rescue analgesia, pain scores and rates of nausea and vomiting.

Results Eighteen studies were included in the current metaanalysis. Quality assessment revealed that only 11 of 18 RCTs

\begin{tabular}{|c|c|c|c|}
\hline & $\begin{array}{l}\text { 24h opioid consumption } \\
\text { MD (95\% CI) }\end{array}$ & $\begin{array}{l}\text { Pain scores at rest at } 2 \text { th } \\
\text { MD }(95 \% \text { CI) }\end{array}$ & $\begin{array}{l}\text { Incidence of nausea and } \\
\text { vomiting } \\
\text { Odds ratio }(95 \% \mathrm{CD})\end{array}$ \\
\hline ESP block vs control & $5.29(-0.55,11.13)$ & $-0.2(-1.41,1.01)$ & $6.46(0.65,64.12)$ \\
\hline QL block vs control & $9.58(1.00,18.15)$ & $1.52(0.74,2.29)$ & $3.24(0.25,42.46)$ \\
\hline TAP block vs control & $5.18(1.68,8.69)$ & $0.78(0.39,1.18)$ & $1.76(0.79,3.93)$ \\
\hline
\end{tabular}

had some concerns regarding overall risk of bias. The results showed quadratus lumborum block was the best intervention for morphine consumption reduction at $24 \mathrm{~h}$ and resting pain scores. Transversus abdominis plane block was also effective in reducing opiate consumption and resting pain scores. However, no techniques were associated with a reduced incidence of postoperative nausea and vomiting. TAP block subgroup analyses revealed that location and timing of plane block may impact the effectiveness of $24 \mathrm{~h}$ opioid consumption reduction.

Conclusions Fascial plane blocks are effective analgesic techniques in total abdominal hysterectomy. However, there are insufficient data for to draw definitive conclusions, further studies are required for QL and ESP blocks.

\section{LESS INVASIVE, MORE EFFECTIVE: SINGLE PUNCTURE COMBINED LUMBAR PLEXUS AND TRANSMUSCULAR QUADRATUS LUMBORUM BLOCKS FOR LONG LASTING UNILATERAL VASCULAR SURGERY PROCEDURES IN FRAGILE PATIENTS}

A Strumia*, M Bernardinetti, F Costa, G Pascarella, E Tomaselli, S Rizzo, LM Remore, F Spinelli, FE Agro. Campus Bio Medico University of Rome, Rome, Italy

\subsection{6/rapm-2021-ESRA. 199}

Background and Aims Peripheral vascular surgery patients commonly present multiple diseases and receive anticoagulants or antiplatelet drugs. Nonetheless, revascularization procedures may last many hours. Thus the risk of a long-lasting general anesthesia may increase while neuraxial blocks may expose patients to an augmented risk of bleeding [1]. Peripheral blocks last longer and guarantee hemodynamic control but may not be adequate for procedures involving the iliac artery.

We present a case of a patient, who underwent revision of an iliac-femoral bypass under a combination of lumbar plexus and quadratus lumborum blocks.

Methods Female 70 y.o., ASA III. Chronic legs ischemia, diabetes, multiple bypass and left toe amputation,

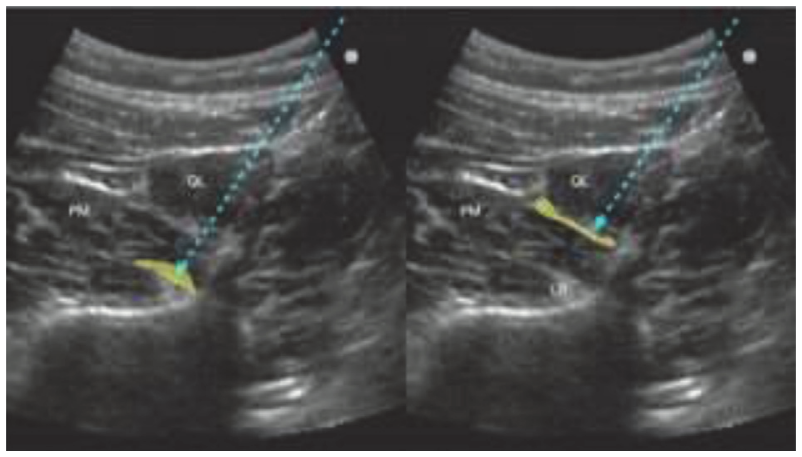

Abstract 199 Figure 1 